means of an adjusting screw, to press lightly against the face of the ebonite ring, and to produce metallic contact with the studs when passing over them. The binding screws around the case of the instrument are connected in serial order with the wires inserted in the bore of the thermometer, and the traverser is in permanent electrical contact with the binding screw $\mathrm{L}$, to which is attached the line-wire.

If the transmitter is intended to convey the signals from more than one thermometer, there are inserted in the ebonite ring, at suitable intervals, three small platinum studs very close together. These studs are not in connection with the thermometers, but with the binding-screw c, which is in permanent connection, through the battery, with earth. By this arrangement the current is shortcircuited whenever the traverser passes over these extra studs, and the three signals sent down the wire in quick succession serve to show that the transmitter has commenced to send signals from another thermometer.

The axis which drives the traverser carries round with it a metallic disk, which is drilled with a hole into which fits, when the clockwork is at rest, a small plug. This plug, which acts as a detent, is attached to the heavier side of a light lever, the opposite end of which is furnished with an iron armature in close proximity to the poles of a very small electro-magniet. One end of the magnet coil is connected with the binding-screw $\mathrm{C}$, and so through the battery with earth, whilst the other end of the coil is connected through the binding-screw M (Figs. 2 and 3 ) with another line-wire which is carried to the observing station, and is capable of being put to earth through an ordinary electric bell-push.

The general arrangement of the whole apparatus is shown in the diagram, Fig. 3. The action of the instrument is as follows:-The line-wire connected with $\mathrm{M}$ is momentarily put to earth at the observing station by depressing the bell-push ; this causes a current to circulate round the coils of the electro-magnet, which, attracting its armature, liberates the detent, and starts the clock. The number of signals now passed down the line-wire by the passage of the traverser over the platinum studs will be a measure of the height of the mercury column in each thermometer. The traverser, having made one complete revolution, is arrested by the falling of the plug into the disk.

It is evident that any number of observing stations can be established along the line-wire, and also that, if desired, the apparatus may be made automatically to register the temperature at any required interval of time. HORACE T. BROWN

\section{THE RECENT DISCOVERY OF THE BODY OF RHINOCEROS MERCKII IN SIBERIA}

$T^{T}$ is a well-known fact that carcases of extinct animals, such as the Mammoth (Elephas primigenius) and Tichorhine Rhinoceros (Rhinoceros tichorhinus) are obtained in a more or less perfect state of preservation in the frozen tundras of Siberia. A memoir recently presented by Dr. Leopold von Schrenck to the Imperial Academy of Sciences of St. Petersburg, ${ }^{1}$ informs us that the most recent discovery of this nature (which too's place in 1877 ) is of a specially interesting character. The remains found upon this occasion turn out, not to belong to either of the above-named animals, but to a distinct species of Rhinoceros, Rhinoceros Merckii (better known in England as Rhinoceros leptorhinus of Owen), which had never been known previously to occur in such a condition. Unfortunately full advantage has not been taken of this extraordinary discovery. Although the carcase, as already mentioned, was found in 1877 , it was not until March, \footnotetext{
I "Das erste Fund einer Leiche, Rhinoceros Merckiz, Jaeg." Von Dr.
Leop. v. Schrenck (Mém. Ac, Imp. Sc. St. Pet, vii série, vol. xxvii. No. 7, Leop.
}

I879, that it came to the knowledge of the Imperial Academy. At the same time the sad fact was communicated that only the head and one foot of the whole body of this extinct monster had been preserved, all the remaining portions having been allowed to drift away into the River Yana, upon the banks of which it had first come to light.

The head in question, after having been exhibited in Moscow, at the Anthropological Exhibition of 1879 , was presented to the Zoological Museum of St. Petersburg, where upon comparison with the Tichorhine Rhinoceros, it was shown to belong, not as had been previously supposed, to that species, but to Rhinoceros Merckii.

Of this specimen, which is naturally reckoned among the greatest treasures of the Imperial collection, Dr. L. von Schrenck now gives us an excellent description, illustrated by several figures, which show that in external as well as (as now already known) in osteological characters, $R$. Merckii presents many salient features to distinguish it from $R$. tichorhinus.

As regards the former distribution of $R$. Merckii, although it was once supposed that this species was confined to Western and Southern Europe, recent researches had already proved that this extinct rhinoceros had a much more extensive range. Besides being found in several localities in Eastern Europe, Brandt, in his excellent Memoir on the Tichorhine Rhinoceroses, has shown that this species formerly existed in Eastern Siberia. It is therefore not now so remarkable that a whole frozen body of this former inhabitant of the Steppes of Siberia should have been discovered on the banks of one of the rivers, preserved frozen during many thousands of years, as we know to have been also the case in the previously obtained specimens of the Mammoth and the Tichorhine Rbinoceros.

\section{NOTES}

WE give on another page an abstract of the revised edition of the proposed statutes on the professoriate promulgated by the Oxford University Commissioners. It is, to say the least, hopeful to find the Commissioners so amenable to criticism and suggestions, and the proposed revised statutes, it will be found, obviate most of the objections which came from all quarters to the harassing and humiliating nature of the first draft. Occupying the position we do in relation to science, we could not but condemn the statutes in their first form. Were we the mouthpiece of the College of Preceptors, then possibly we might not have objected to the Oxford professors being legislated for as if they were merely elementary school-teachers; but as we are bound to consider the interests of science and its advancement, and as we believe one of the chief duties of an Oxford professor, as of a German or a French professor, to be original research, we could not but consider the statutes in their first form as a serious blunder.

ON Monday, March 15, the Paris Academy of Sciences held its annual sitting, when the prizes for 1880 were delivered. M. Ed. Becquerel was in the chair. $\mathrm{He}$ opened the sitting by an eloge of M. Michel Chasles, who died quite recently, and who was one of the most popular members of the Academy. At the end of his address he reminded his fellow members of the completion of the great work of M. Milne-Edwards, which has lasted for a quarter of a century. The great prize for mathematics was awarded to M. Halphen, with honourable mention to M. Poincarre; the Poncelet Prize to M. Leonte, engineer of the machinery constructed by the Government. A sum of 3000 francs was awarded to M. Ader for having advanced in an essential manner phonetic telegraphy (also telephony). The Trémont Prize was awarded to $M$. Vinot, the editor of the only astronomical paper published in France, and the founder of the only astronomical society. M. Dumas, with 